\title{
Gender Sensitive Blindness Prevention Intervention in the Niger Delta Region of Nigeria II: A report of a free cataract surgical service for women
}

\section{GE Patrick-Ferife MSc (CEH) FNMC ${ }^{1}$, RE Duke MSC (CEH) FWACS ${ }^{2}$, EN Ogbedo FWACS ${ }^{3}$, F Omoraka $^{4}$}

${ }^{1}$ Ministry of Health, Asaba and EyeCARE Health Initiative, Delta State, Nigeria

${ }^{2}$ University of Calabar Teaching Hospital, Calabar, Nigeria

${ }^{3}$ Okwe General Hospital, Okwe - Asaba. Delta State, Nigeria

${ }^{4}$ Central Hospital, Sapele, Delta State, Nigeria

\section{SUMMARY}

Background: Gender issues in eye care are a global priority. Women have been recognized to face challenges in eye care. This includes a higher prevalence of disease conditions such as cataract to service delivery in which it is noted that they take up services especially for cataract surgery less than their male counterpart. This report seeks to document the experience and outcome of this organized gender-sensitive eye care project and in addition, make recommendations for future gender programmes. Women in the state were invited to participate in a free cataract surgical eye camp project. A talk on HIV was given at each centre and women willing to have free HIV testing were tested and counselled accordingly.

Methods: A total of four thousand two hundred and thirty nine (4239) women were examined between 1st July and $30^{\text {th }}$ September 2007. Eye operations were performed on 261 ( $6 \%$ ) women during the duration of this project. Extra capsular cataract surgery with intraocular lens implantation was performed in 185 out of the 261 eye surgeries.

Of the 4239 women who presented, a total of nine hundred and twenty three women (923) voluntarily screened for HIV. Out of these, thirty eight (38) women tested positive, of which 35 accepted counselling and commenced treatment.

Two thousand five hundred and sixty-six (2566) 61\% of participants at the eye camp were given reading glasses; most of these women were civil servants (teachers).
Results: A female only surgical cataract eye camp is possible. It is convenient, economical and beneficial to have a collaborative programme with the committee on HIV/AIDS. This project was a successful strategy to reduce blindness, poverty and ensure empowerment of women. Recommendations are made towards a holistic approach in the organization of cataract surgical eye camps and for women.

Key words: female, HIV, cataract, community eye camp

\section{INTRODUCTION}

Blindness is an increasing global health problem affecting over 45 million people worldwide with women making up two-thirds of the total blind population. ${ }^{1}$ Gender issues in eye care are a global priority. Very few women utilize eye care services, more women are blind or visually impaired more than men from eye disease such as cataract, glaucoma, presbyopia and refractive errors.and It has been shown that, women have a higher biological predisposition to cataract. ${ }^{2}$

In 2007, in Delta State, located in the South -South geopolitical zone of Nigeria, a non government organization (NGO) Master Care Foundation "ICare", partnered with the EyeCARE Health Initiative an indigenous eye care NGO. The objectives of the partnership were to screen women for cataract and provide free cataract surgery with intraocular lens implantation, screen all women for refractive errors/presbyopia and provide free reading spectacles and also to create awareness and counselling about HIV/AIDS, carry out free HIV testing and enroll such women in the free anti-retroviral drug programme of the state. 
This report seeks to document the experience and outcome of this organized gender-sensitive eye care project and in addition, make recommendations for future gender programmes.

\section{METHODOLOGY}

Women in the state were invited to participate in a free cataract surgical eye camp project, through announcements in the print, electronic media, by local town criers for remote villages and verbal communications. The project was phased and conducted in three selected government owned hospitals in the three senatorial districts of the state. This project was conducted between $1^{\text {st }}$ of July 2007 and $31^{\text {st }}$ September 2007.

All the women that presented themselves were screened based on a flow chart and ocular findings recorded in the eye examination forms. A talk on HIV was given at each centre and women willing to have free HIV testing were tested and counselled accordingly.

Extra capsular cataract surgery with intraocular lens implantation was performed on selected patients. The selection criteria were bilateral mature cataracts, only-eyed patients blind from cataract and no perception of light with associated mature cataracts in which the patient felt concerned about appearance. All surgeries were performed in selected secondary eye centres that had resident consultant ophthalmologist coverage.

A questionnaire with only four questions was administered, asking why those in need of cataract surgery had not done the operation.

\section{RESULTS}

A total of four thousand two hundred and thirty nine (4239) women were examined between 1 st July and $30^{\text {th }}$ September 2007. Two thousand five hundred and sixty six (2566) 61\% of them were given reading glasses most of these women were civil servants (teachers) and (261) 6\% eye operations were performed during the duration of this project. Out of the 261 eye operations, 185 women had cataract surgery. Other surgeries performed at the camp included trabeculectomy, pterygium, and granuloma excision.

Of the 4239 women who presented, a total of nine hundred and twenty three women (923) voluntarily screened for HIV. Out of these, thirty eight (38) women tested positive, of which 35 accepted counselling and commenced treatment. The remaining three HIV positive women received counselling but rejected commencing treatment at that moment. They were followed up after the eye camp and are now on antiretroviral therapy. Two of the thirty eight women had cataract surgery at the camp.
Table 1. Age group, number and percentage of women who presented themselves for the programme

\begin{tabular}{c|c|c}
\hline Age group & Number & Percentage \\
\hline $30-39$ & 1001 & 24 \\
$40-49$ & 1211 & 28 \\
$50-59$ & 1001 & 24 \\
$60-69$ & 920 & 22 \\
70 \& above & 106 & 2 \\
\hline Total & 4239 & 100 \\
\hline
\end{tabular}

Table 2. Age group, number and percentage of women who had cataract surgery

\begin{tabular}{c|c|c}
\hline Age group & Number & Percentage \\
\hline $30-39$ & 2 & 1 \\
$40-49$ & 5 & 3 \\
$50-59$ & 59 & 32 \\
$60-69$ & 75 & 40 \\
70 \& above & 44 & 24 \\
\hline Total & 185 & 100 \\
\hline
\end{tabular}

Table 3. Presenting visual acuity in 185 women

\begin{tabular}{c|c|c}
\hline $\begin{array}{c}\text { Grade of visual } \\
\text { acuity }\end{array}$ & Number & Percentage \\
\hline$>6 / 18$ & 0 & 0 \\
$6 / 18-6 / 60$ & 0 & 0 \\
$<6 / 60-3 / 60$ & 2 & 1 \\
$<3 / 60-$ PL & 181 & 98 \\
NLP & 2 & 1 \\
\hline Total & 185 & 100 \\
\hline
\end{tabular}

Table 4. Number of patients in relation to the grade of pinhole visual acuity on the first post operative day

\begin{tabular}{c|c|c}
\hline $\begin{array}{c}\text { Grade of visual } \\
\text { acuity }\end{array}$ & Number & Percentage \\
\hline$>6 / 18$ & 160 & 86 \\
$6 / 18-6 / 60$ & 22 & 12 \\
$<6 / 60-3 / 60$ & 0 & 0 \\
$<3 / 60-$ PL & 1 & 1 \\
NLP & 2 & 1 \\
\hline Total & 185 & 100 \\
\hline
\end{tabular}

Table 5. Reasons for late presentation for cataract surgery

\begin{tabular}{l|r|c}
\hline Reason for late presentation & Number & Percentage \\
\hline No money & 153 & 83 \\
I was busy and no time & 16 & 9 \\
Nobody to bring me & 8 & 4 \\
Did not know where to go & 2 & 1 \\
Others & 6 & 3 \\
\hline Total & 185 & 100 \\
\hline
\end{tabular}




\section{DISCUSSION}

Delta State has a population of four million ninety eight thousand, three hundred and ninety one $(4,098,391)$; women comprise $65 \%$ of this number. The need and the poor uptake of eye services by women indicate that this group requires special attention and thus may require a female-gender focussed eye programme, especially cataract surgical services.

The two patients that presented with No Perception of Light in one eye had cataract extraction performed, without intraocular lens implantation. It has been noted that one of the causes of poor outcome in cataract extraction is poor patient selection. ${ }^{2}$ Though these patients knew they would not regain vision they were more concerned about their cosmetic appearance, and for this reason they requested the surgery. For women therefore, a good visual outcome while important is not all that matters in making an informed decision about surgery.

From a hospital based study in Cape town, South Africa, it was seen that from the patient factor perspective, the common barriers to the uptake of cataract surgery included, transport issues, availability of people to accompany , support, distance to travel, fear and availability of education and information. Others were lack of motivators and socio-economic consequences for patient and accompanying persons. ${ }^{3}$ This report while not applying the same methodology obtained a similar result. The main reason for delay in presentation was that the women had no money. This was not surprising, as it has been noted that poor rural women often have less disposable income, or control of finances, than men as a significant barrier to uptake of cataract services for women. ${ }^{3}$ The second reason was that, they were busy and had no time to travel to a secondary surgical centre for assessment and surgery, other causes included, long distance to travel. In Africa, women play a major role in income generation and care for the family.

Outcome of surgery was good with extra capsular cataract extraction and intraocular implant, as was seen in over $80 \%$ of women that had a first day pin hole visual acuity of at least $6 / 18$. Some patients had morbid conditions co-existing with the cataract; the commonest problem was advanced glaucoma. This was responsible for visual impairment noted after surgery.

The commonest cause for attendance to an adult eye clinic is for the treatment of refractive error and presbyopia. Similarly at the eye camp clinics most patients had presbyopia. Most of the women who received reading glasses were teachers.
One major significant benefit of attendance to this camp was the collaboration with the action committee on HIV/AIDS prevention. Usually cataract camps focus only on eye care, however, through this collaborative effort women became educated and willing to be tested; those in need of referral were referred for treatment and follow up by a professional team, while those that required surgery had their surgery performed. This combination of services has not been noted in any female cataract surgery camp.

The reactions of a number of these women to their HIV status especially when negative were very dramatic.

\section{CONCLUSION}

A strategy to reduce poverty, blindness and empowerment of women through targeted eye care service promotion, education and delivery through a female surgical cataract eye camp is possible. It may also be convenient, economical and beneficial to have a collaborative program such as was executed with the team from the action committee on HIV/AIDS in Delta state.

\section{RECOMMENDATIONS}

It is suggested that more female targeted eye health initiatives should be delivered and more female cataract eye camps should be promoted and executed.

No perception of light (NPL) eyes have traditionally being left without surgery, however from this project we suggest that counselling and surgery should be offered for such eyes for cosmetic reasons especially in women.

School eye health programmes should not be targeted at children alone, but such programmes can also serve as a strategy to educate and encourage the teachers to test for refractive errors and presbyopia and refer them to comprehensive secondary eye centres where they can obtain an affordable pair of spectacles.

\section{REFERENCES}

1. Cook C.How to improve the outcome of cataract surgery. Community Eye health Journal 2000; 13(35): 37-38.

2. Shah A. Barriers to the uptake of cataract surgery for women in urban Capetown. Community Eye Health J 2005; 18(53): 80 .

3. Lewallen, S., Courtright, P. Gender and use of cataract surgical services in developing countries. Bulletin of the World Health Organization 80.4 (2002): 300-303. 